Journal of Engineering and Applied Sciences 6 (1): 64-70, 2011

ISSN: 1816-949X

(C) Medwell Journals, 2011

\title{
Finite Element Analysis of Drillstring Lateral Vibration
}

\author{
Jamal Zare, Seyed Jalalodin Hashemi and Gholamreza Rashed \\ Department of Drilling Engineering, Petroleum University of Technology, Ahvaz, Iran
}

\begin{abstract}
Lateral vibration is recognized as the leading cause of drillstring and BHA failures, shocks and severe damages to borehole wall. This study presents a finite element model using ANSYS software to investigate the drillstring lateral vibrations in slightly deviated wells. The analysis proceeds in two stages. At first, a nonlinear static analysis is performed to determine the effective length of the string where it is free to vibrate in the lateral direction. The second stage consists in modal, harmonic and transient dynamic analyses to obtain the lateral vibration modes and natural frequencies, frequency response and time dependent response, respectively. The modeling is developed in the presence of mud, friction and nonlinear contact between drillstring and wellbore wall. The effects of drilling mud, drillstring length, hole inclination and WOB are considered. The model was compared with experimental and simulated results obtained from several BHA configurations giving excellent results.
\end{abstract}

Key words: Drillstring, finite element model, lateral vibration, nonlinear contact model, BHA, Iran

\section{INTRODUCTION}

Lateral vibration of the drillstring is known to result in fatigue failures, excessive wear, washouts and Measurement While Drilling (MWD) tool failures. It often caused by drillcollar eccentricity, leading to centripetal forces during rotation, named as whirling. The initial eccentricity of the drillcollar can result from drillcollar sag due to gravity or high compressive loads owing to Weight on Bit (WOB) or Mass imbalance such as that created by MWD tools. Bit-formation interactions and fluctuations of the WOB are the other mechanisms that induce transverse oscillations. It is of prime importance for the drilling industry to detect and minimize the excessive lateral displacement of the drillstring while it rotates. This may reduce drilling costs by avoiding a breakdown of the drillstring components either instantaneously or by fatigue.

If drillstring excites near one of its natural frequencies, severe vibrations and impacts with the wellbore wall will appear. Such impacts create an overgauge hole and produce problems with directional control of the well. To solve the problem, one should analyze the drillstring to find its natural frequencies and modal shapes and then by changing the drilling parameters, avoids the resonance of the drillstring.

In order to optimize the drilling performance, various dynamic models have been proposed until now, employing both the analytical and numerical techniques. The analytical approach has been the basis of early analyses. Jansen (1991) derived a simple two degree of freedom lumped parameter model of the drillstring to study the whirling stability. Dunayevsky and Abbassian (1998) presented the similar model taking into account coupling between bending and torsional vibrations. Yigit and Christoforou $(1996,1998)$ modeled the drillstring based on Lagrangian formulation and the assumed mode method. One model accounts for the coupling between axial and transverse vibrations and the other between torsional and transverse vibrations.

Because of the great complexity of the problem, recently advanced numerical methods is the most widely used tool for drillstring static and dynamic analysis. In this direction, Shyu (1989) studied the coupling between axial and lateral vibrations and the whirling of drillstring using finite difference method. Besaisow and Payne (1988) studied the excitation mechanisms and resonances that cause Bottomhole Assemblies (BHA) vibrations during drilling operations based on data gathered in a well test. Burgess et al. (1987) used finite element method to model the lateral vibration of drillstring. They performed a static nonlinear analysis to find the location where the string above the last stabilizer touches the wellbore wall. Then using the drillstring length from bit to this point, they evaluated the response of the string by harmonic analysis disregarding the effects of drilling mud. Apostal et al. (1990) developed a three dimensional finite element model to investigate the harmonic response of BHA. Damping in the form of proportional, structural and viscous were included in their model. Khulief and Al-Naser (2005) used the Lagrangian approach to formulate the finite element model of a rotating vertical drillstring.

Corresponding Author: Jamal Zare, Department of Drilling Engineering, Petroleum University of Technology, Ahvaz, Iran 
In this study using ANSYS software, a finite element model is presented to describe the lateral vibration of drillstring in near vertical oilwells. Initially, static analysis is performed to identify the first point above the last stabilizer where the drillcollars lie against the wellbore wall known as cut-off point. Subsequently, dynamic behavior of drillstring is exhibited by modal, harmonic and transient analyses to achieve mode shapes and natural frequencies, frequency response and time dependent response, respectively. It is assumed that the wellbore is perfectly in gauge in place of bit and stabilizers and the contact between stabilizers and the wellbore is a point contact. The effect of parameters such as hole inclination, WOB, drillstring length and rotary speed are considered in the presence of drilling mud and friction between drillstring and borehole wall. In order to model the contact between drillstring and borehole wall, the nonlinear beam to beam contact model with CONTA176 and TARGE170 elements are used.

\section{MATERIALS AND METHODS}

Finite element model: In this research, the drillstring and the well formation are modeled by beam 188 element which is a linear 2-node beam element in 3-D and has 6 degrees of freedom at each node including translations in the $\mathrm{x}, \mathrm{y}$ and $\mathrm{z}$ directions and rotations about the $\mathrm{x}, \mathrm{y}$ and $\mathrm{z}$ directions. It is suitable to model slender beam structure, large deformation and finite strain. This element is based on Timoshenko beam which is a first order shear deformation theory.

It can be used with any beam cross-section defined via SECTYPE and SECDATA commands. Beam 188 ignores any real constant data and can receive properties such as density and damping in material properties section. The meshed model of drillstring and borehole formation is shown in Fig. 1. To simulate the formation around the wellbore, a hollow cylinder with the internal radius equal to external radius of bit and 3 feet thick is used. The contact effect between drillstring and wellbore wall is the most important factor which causes the nonlinearity and complexity in drillstring vibrational equations. To make a model for beam to beam contact effect, CONTA176 and TARGE170 elements are used. CONTA176 represents contact and sliding between 3-D line segments (TARGE170) and a deformable line segment defined by this element. Internal contact where a beam or a pipe slides inside another hollow beam or pipe is one of its applications utilized here. The contact element coincides with external surface of drillstring while the target coincides with borehole wall as shown in Fig. 2. Contact is detected when two circular beams touch or overlap each other. The non-penetration condition for beams with a circular cross section and internal contact can be defined as:

$$
g=\left|r_{t}-r_{c}\right|-d \leq 0
$$

Where, $r_{c}$ and $r_{t}$ are the radii of the cross sections of the beams on the contact and target sides, respectively and $\mathrm{d}$ is the minimal distance between the two beams which also determines the contact normal direction. Contact occurs for negative values of $\mathrm{g}$. The value of 0.2 is assumed for the contact friction coefficient in static and dynamic analyses.

In this study, a drillstring of the specification adopted in Besaisow and Payne (1988) and shown in Table 1 is used for all analyses. Table 2 and 3 show the other descriptions of drillstring in Table 1 with the same BHA, merely to examine the effect of length and to compare with measured downhole data (Besaisow and Payne, 1988). The geometry of the drillstring in a slightly inclined well is shown in Fig. 3.

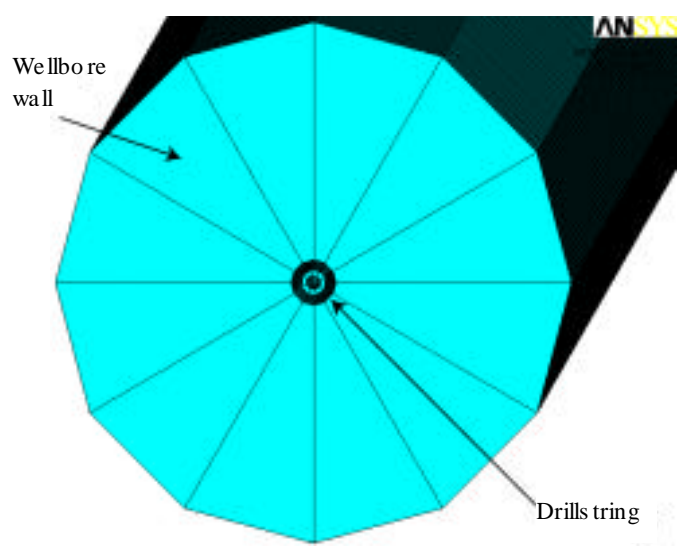

Fig. 1: Meshed model of drillstring and borehole formation

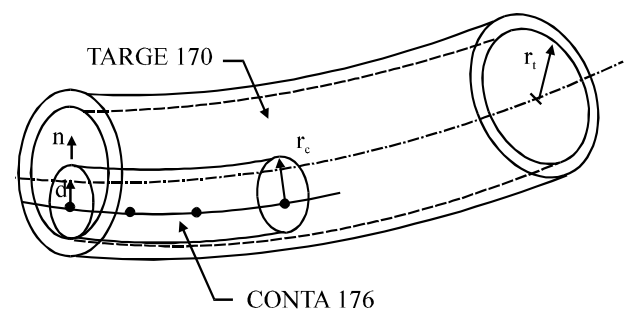

Fig. 2: Beam to beam contact and target elements

\begin{tabular}{|c|c|c|c|c|}
\hline Name & Length (ft) & O.D. (in) & I.D. (in) & Aggregate length (ft) \\
\hline Bit & 3.25 & 6.25 & -- & 3.3 \\
\hline Stab. & 6.40 & 4.75 & 2.25 & 9.7 \\
\hline $\mathrm{DC}$ & 30.80 & 4.75 & 2.25 & 40.5 \\
\hline Stab. & 6.60 & 4.75 & 2.25 & 47.0 \\
\hline $\mathrm{DC}$ & 529.10 & 4.75 & 2.25 & 576.2 \\
\hline HWDP & 121.90 & 3.50 & 2.06 & 698.1 \\
\hline
\end{tabular}




\begin{tabular}{lcccc}
\multicolumn{5}{l}{ Table 2: Drillstring no. 2 specification } \\
\hline Name & Length (ft) & O.D. (in) & I.D. (in) & Aggregate length (ft) \\
\hline Bit & 3.25 & 6.25 & -- & 3.3 \\
Stab. & 6.40 & 4.75 & 2.25 & 9.7 \\
DC & 30.80 & 4.75 & 2.25 & 40.5 \\
Stab. & 6.60 & 4.75 & 2.25 & 47.0 \\
DC & 529.10 & 4.75 & 2.25 & 576.2 \\
HWDP & 30.42 & 3.50 & 2.06 & 606.0 \\
\hline
\end{tabular}

\begin{tabular}{lcccc}
\multicolumn{5}{l}{ Table 3: Drillstring no. 3 specification } \\
\hline Name & Length (ft) & O.D. (in) & I.D. (in) & Aggregate length (ft) \\
Bit & 3.25 & 6.25 & -- & 3.3 \\
Stab. & 6.40 & 4.75 & 2.25 & 9.7 \\
DC & 30.80 & 4.75 & 2.25 & 40.5 \\
Stab. & 6.60 & 4.75 & 2.25 & 47.0 \\
DC & 343.00 & 4.75 & 2.25 & 390.0 \\
\hline
\end{tabular}

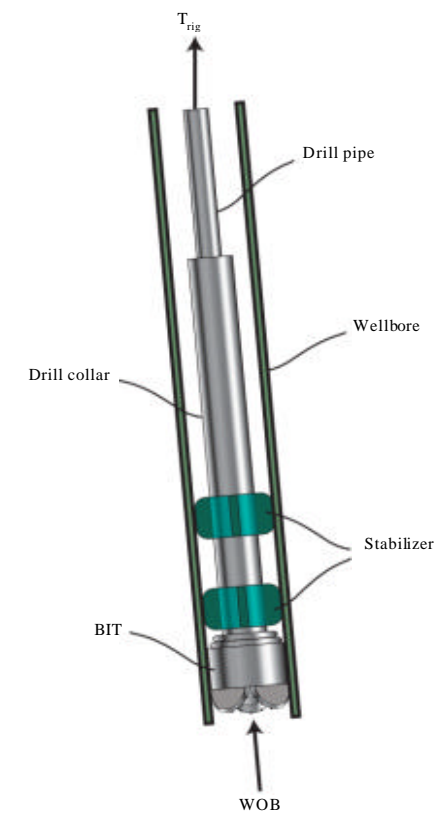

Fig. 3: Geometry of the drillstring

Mechanical properties of drillstring, formation and drilling mud is shown in Table 4. It is assumed that the material of the drillstring is elastic, homogeneous and isotropic.

Boundary conditions: Drillstring boundary conditions are defined as:

- At the stabilizers position, radial deflection is constrained while axial translation and rotation about drillstring axis are found

- At the place of bit, drillstring can rotate about longitudinal axis of drillstring and support axial and radial forces

- At the location of rotary table, radial displacement is constrained while rotation around drillstring axis is released
Table 4: Mechanical properties of drillstring, formation and mud

\begin{tabular}{ll}
\hline Properties & Values \\
\hline Drillstring & \\
Modulus of elasticity $\left(\mathrm{lb} \mathrm{ft}^{-2}\right)$ & $4.32 \times 10^{9}$ \\
Density (slug $\mathrm{ft}^{-3}$ ) & 15.18 \\
Poisson ratio & 0.25 \\
Formation & \\
Modulus of elasticity $\left(\mathrm{lb} \mathrm{ft}^{-2}\right)$ & $4 \times 10^{8}$ \\
Mud & \\
Density (slug $\mathrm{ft}^{-3}$ ) & 1.52 \\
Viscosity (slug ft & $\mathrm{sec}$ ) \\
\hline
\end{tabular}

Dynamic effects of mud: When a structural component vibrates in a viscous fluid, the presence of the fluid gives rise to a reaction force which can be interpreted as an added mass and a damping contribution to the dynamic response of the component (Chen et al., 1976). Added mass due to acceleration and damping due to drag force known to be dependent on fluid properties in particular, density and viscosity are presented in detail in the Appendix A. The values of 20.32 slug $\mathrm{ft}^{-3}$ for equivalent density of drillstring and 0.03 for damping ratio are attained, neglecting damping associated with internal friction in the solid material and losses at the support location

\section{RESULTS AND DISCUSSION}

\section{Finite element analyses}

Static analysis: As mentioned before, the effective length of drillstring plays an important role in dynamic analysis. In static analysis by simulation of drillstring in near vertical well, the cut off point where the effective BHA terminates is identified. This point is located above the second stabilizer. Then by using UPGEOM command in ANSYS software, the static equilibrium state is imported in subsequent dynamic analyses.

This command updates the model geometry according to the displacement results of static analysis and creates a revised geometry at the deformed configuration for the other analyses. Static deformation of drillstring shown in Table 1 with 1 degree deviation from vertical and $15 \mathrm{klb}$ WOB indicated in Fig. 4 where most of its length rests on the borehole wall. Neglecting the effect of mud, it reveals that cut off point is 114 feet from the bit which is in agreement with 113 feet reported by (Burgess et al., 1987). The cut off point moves upwards and will be 120 feet from the bit if the mud buoyancy effect is regarded. For this sake, the buoyancy correction coefficient must be multiplied in drillsring density according to (Lee, 1991). This value will be equal to 0.809 for the 1.52 slug $\mathrm{ft}^{-3}$ mud density.

Modal analysis: The objective of modal analysis is to specify lateral natural modes and frequencies of the 


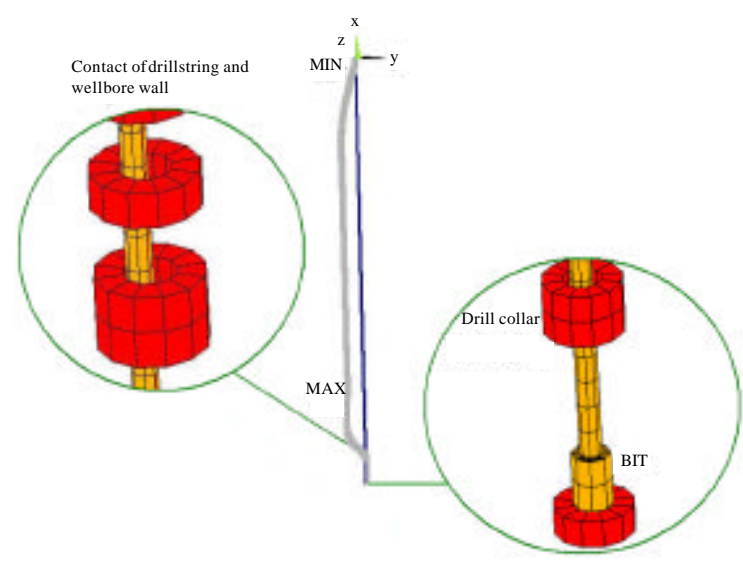

Fig. 4: Static deformation of drillstring no. 1

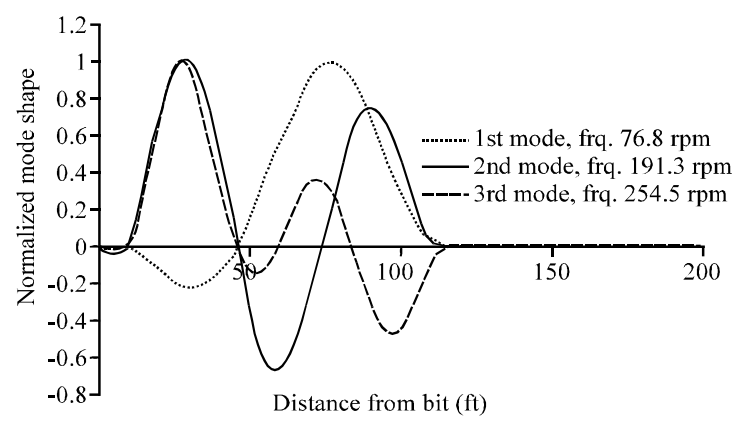

Fig. 5: First three mode shapes and natural frequencies of drillstring no. 1

drillstring. If external excitations exert at such frequencies, the resonance happens and the amplitude of lateral vibration increases exceedingly, drillstring strikes wellbore wall and creates large shocks. To prevent happening of this destructive phenomenon, the frequency of external loads must be far from natural frequencies.

Modal analysis reveals that the effective length of drillstring affects the lateral natural mode shapes. Mode shapes of three main frequencies for drillstring no. 1 are attained and shown in Fig. 5 disregarding the mud effects. The mode shape curves tend to zero 114 feet from the bit at cut off point.

As shown in Table 5, results are satisfactory comparing with (Burgess et al., 1987). Lateral natural frequencies of drillstrings in Table 1 through 3 with mud effects are shown in Table 6 (in 1 degree deviated well and $8 \mathrm{klb}$ tensile force on the first node on the rotary table place).

To evaluate the accuracy of the model presented in this study, a comparison between experimental data in Besaisow and Payne (1988) and ANSYS outcomes is carried out as shown in Table 7 giving excellent results.
Table 5: Comparison of three main frequencies of drillstring no. 1 with (Burgess et al., 1987) without mud effect

\begin{tabular}{lllll}
\hline & & \multicolumn{2}{l}{ Natural frequency (Hz) } & \\
& Effective & - & - \\
Comparison & length (ft) & 1st & 2nd & 3rd \\
\hline Ansys model & 114 & 1.23 & 3.14 & 4.19 \\
Burgess et al. (1987) & 113 & 1.25 & 3.15 & $*$ \\
\hline
\end{tabular}

*Not reported

Table 6: Main natural frequencies of three drillstrings included mud effect

\begin{tabular}{|c|c|c|c|}
\hline \multirow[b]{2}{*}{ Types } & \multicolumn{3}{|c|}{ Natural frequency $(\mathrm{Hz})$} \\
\hline & 1 st & 2nd & 3rd \\
\hline Drillstring no. 1 & 0.78 & 2.25 & 3.28 \\
\hline Drillstring no. 2 & 0.88 & 2.27 & 3.37 \\
\hline Drillstring no. 3 & 1.84 & 3.21 & 6.03 \\
\hline
\end{tabular}

Table 7: Comparison of ANSYS reaults and measured data

\begin{tabular}{lcc}
\hline Types & $\begin{array}{c}\text { Natural frequency } \\
\text { from ANSYS (Hz) }\end{array}$ & $\begin{array}{c}\text { Empirical results } \\
\text { from Besaisow (Hz) }\end{array}$ \\
\hline Drillstring no. 1 & 3.28 & 3.40 \\
Drillstring no. 2 & 3.37 & 3.33 \\
Drillstring no. 3 & 3.21 & 3.36 \\
\hline
\end{tabular}

Harmonic analysis: Harmonic analysis is performed to achieve the frequency response of the drillstring. The result of this analysis is depicted for the lateral displacements versus frequency of the axial load tolerated at the first node in the place of rotary table as the excitation node. The onset of resonance phenomenon is identified by appearance of spikes on harmonic plot. It can be used to interpret which points in the BHA are subject to large banding stresses.

For drillstring no. 1 with regarding the added mass and damping due to drilling mud, the influences of deviation angle and WOB on harmonic response for a single point between two stabilizers where MWD tool located there, are considered. Also the effect of drillstring length for two different points (one point between two stabilizers and the other above the second stabilizer) are illustrated. For drillstring no. 1 located in $1^{\circ}$ deviated well at the presence of mud, it was evident that $15 \mathrm{klb}$ WOB is equivalent to $8 \mathrm{klb}$ tensile force on the place of rotary table. The harmonic responses for 25 and 75 feet from the bit in the presence of mud are shown in Fig. $6 \mathrm{a}, \mathrm{b}$ and compared with results in the absence of mud. Obviously, the added mass will decrease the drillstring natural frequencies and damping lessens its amplitude. Figure $7 \mathrm{a}, \mathrm{b}$ shows the harmonic analysis results for drillstrings no. 1 through 3 in one point between two stabilizers and the other above the second stabilizer, respectively. It is assumed the tensile force on the first node is constant and equal to $8 \mathrm{klb}$. These clearly show as the total length of drillstring increases, the natural bending frequencies decrease. Thus, the rotary speed that is not critical at a given depth may become critical as drilling progresses into deeper sections. The 


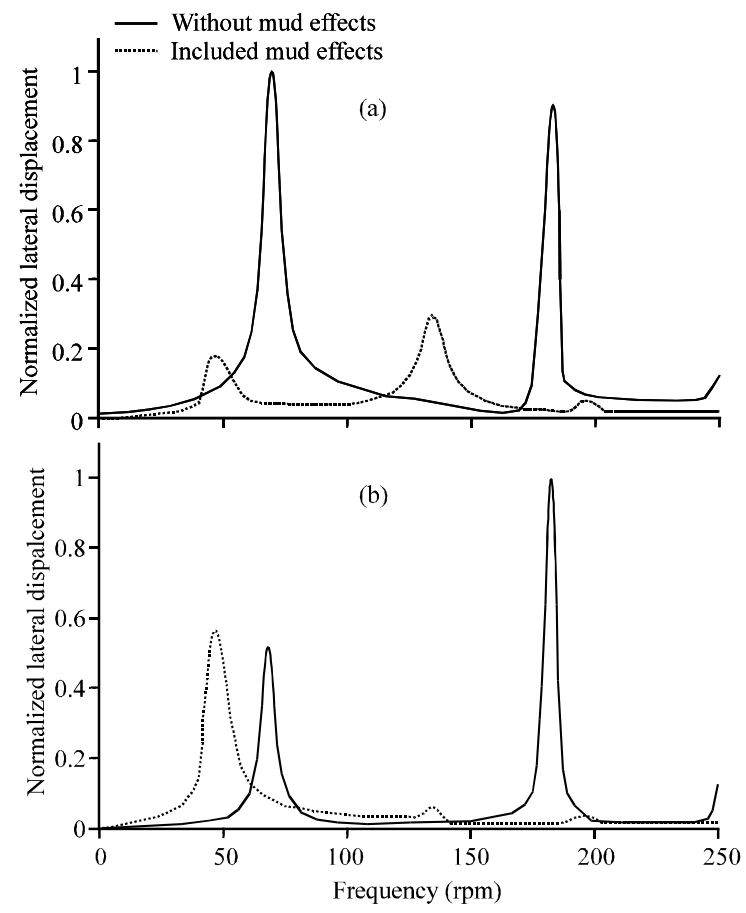

Fig. 6: Effect of mud on natural frequencies of drillstring no. 1 ; a) 25 feet from the bit; b) 75 feet from the bit
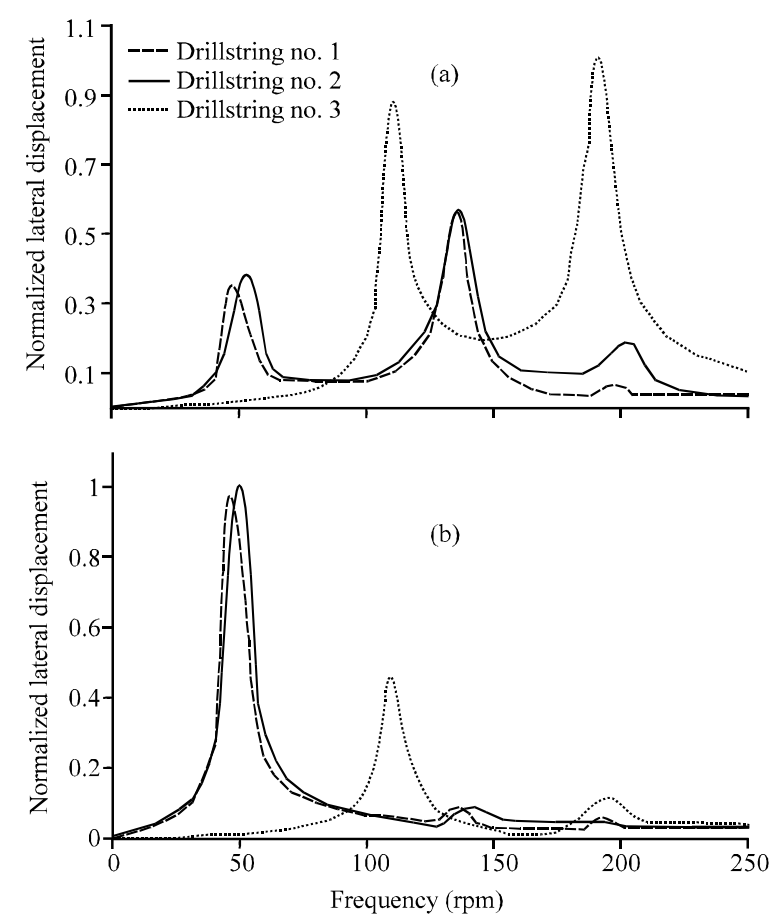

Fig. 7: Effect of length on harmonic response drillstring in point; a) 25 feet from the bit; b) 75 feet from the bit

inversed analytic relation of natural frequencies with the length square for a beam, confirms soundness of the

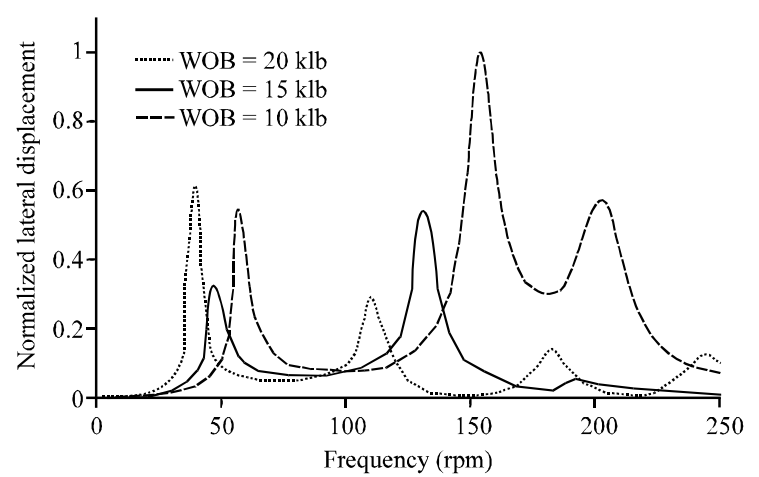

Fig. 8: Effect of WOB on harmonic response of drillstring no. 1

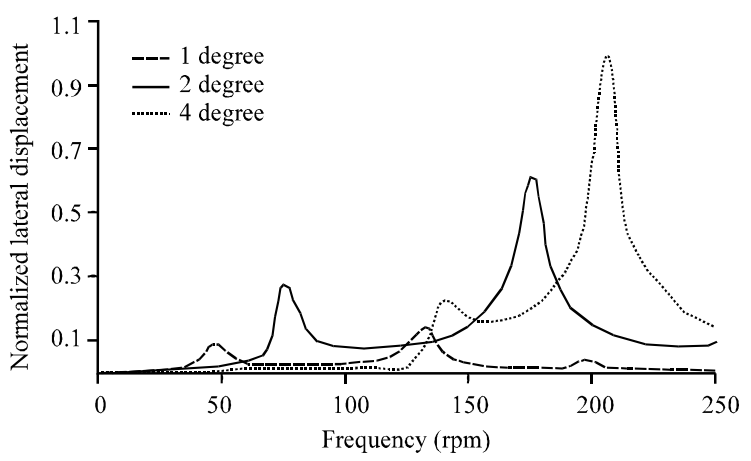

Fig. 9: Effect of hole angle harmonic response of drillstring no. 1

results trend. Figure 8 shows the effect of varying the WOB and hence the effect of the neutral point on the first three bending frequencies for drillstring no. 1 . The cut off point moves downwards and resonant frequencies shift upwards as the WOB increases (as would be expected from the shorter component).

In Fig. 9, the influence of the inclination angle on the resonant frequencies is demonstrated. It shows that the more the hole inclination, the less the effective length and the higher the resonant frequencies.

Transient analysis: In this analysis, time dependent response of dynamic behavior of drillstring detailed in Table 1, situated in a 1 degree inclined well with $15 \mathrm{klb}$ WOB is obtained. Lateral deflection for two different points as a function of time is plotted at 100 and $135 \mathrm{rpm}$ rotary speeds. The rock/bit interaction is another source of excitation used here. To model 3 cone bit and hard rock interaction, an axial excitation with amplitude of 0.1 inch and a frequency of $3 \omega \mathrm{rpm}(0.1 \sin 3 \omega \mathrm{t})$ is necessary to apply on the bit (Dunayevsky et al., 1993; Khulief and Al-Naser, 2005). Notice that mass imbalance or bent pipe due to static deformation causes excitation primarily in the 

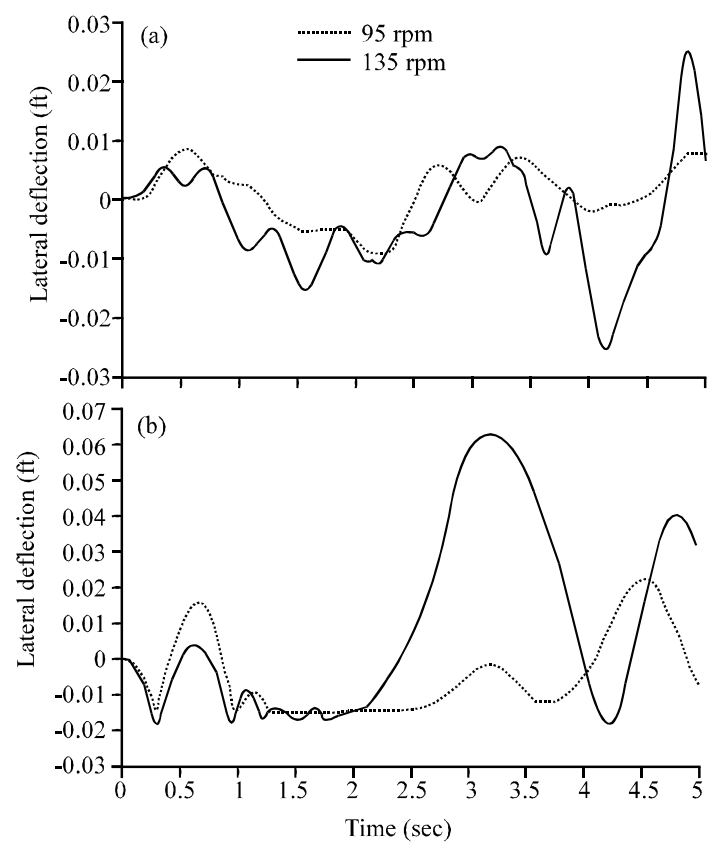

Fig. 10: Time dependent behavior of drillstring no. 1 at $90 \mathrm{rpm}$ and $135 \mathrm{rpm}$ rotary speeds at a) 25 feet and b) 250 feet from the bit

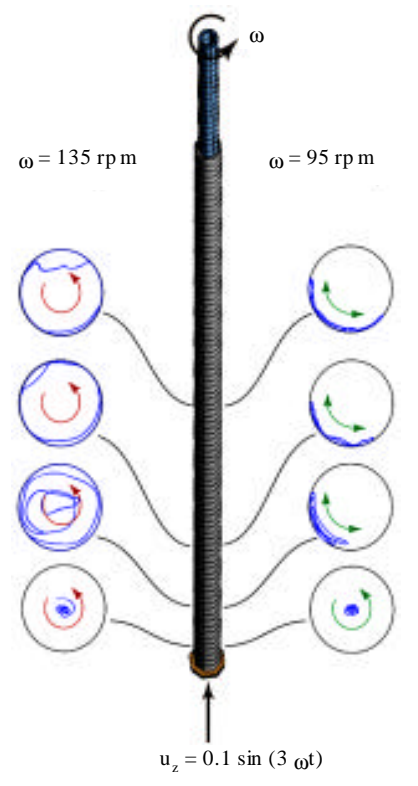

Fig. 11: Orbital trajectories at 25,75, 150 and 300 feet from the bit in the BHA

lateral direction that is on the order of frequency $1 \times \omega$ (Besaisow and Payne, 1988). Lateral deflections for 25 and 250 feet from the bit during the first $5 \mathrm{sec}$ is shown in Fig. 10 at 95 rpm rotary speed. Because this angular velocity is not close to any critical frequencies, the lateral displacements remain in low level, especially at the point located between two stabilizers. A similar scheme is depicted for identical points at $135 \mathrm{rpm}$ rotary speed. In view of the fact that this angular velocity is close enough to second resonant frequency, the lateral displacements rise up seriously relative to the previous case until at 250 feet from the bit, impacts with the wellbore wall.

Predicted orbital trajectories for various locations in the BHA are shown in Fig. 11 while rotary speeds stay 95 and $135 \mathrm{rpm}$ (second natural frequency of drillstring no. 1). It shows results from time domain simulations conducted to evaluate the consequences when the critical speed associated with rock/bit interaction is not avoided. At critical rotary speed, the whirling motion typically propagates quickly throughout the BHA.

\section{CONCLUSION}

A finite element dynamic model of the vibrational characteristics of rotating drillstring is developed using ANSYS software. It can be invaluable in the prevention of vibration induced damage to sensitive BHA components. The model identifies the critical rotary speeds at which severe drillstring vibration can occur. For field application with respect to height of peaks and defining dangerous and nondangerous regions, the model can be used to determine safe operation ranges of rotary speed or to change $\mathrm{BHA}$ configurations to minimize failure risk. As a rule of thumb, it can be inferred the more mass and longer the drillstring or less the WOB or the more vertical the hole or denser the mud, the lower the lateral resonant frequencies. In comparison with the experimental data, high accuracy of the model presented here in predicting the natural bending frequencies make it a good candidate to use in the modeling of drillstring vibration problems by drilling engineers.

\section{ACKNOWLEDGEMENT}

The researchers greatly appreciate the support provided by Petroleum University of Technology during this research.

\section{APPENDIX}

The effect of mud including added mass and damping can be written as (Chen et al., 1976):

$$
\begin{aligned}
& M_{\text {adjusted }}=M_{\text {string }}+C_{M} \times M_{\text {disp }} \\
& \zeta=\frac{1}{2}\left(\frac{M_{\text {disp }}}{C_{M} M_{\text {disp }}+M_{\text {string }}}\right) H
\end{aligned}
$$

Where: 
$\mathrm{M}_{\text {disp }}=$ The mass of displaced mud

$\mathrm{C}_{\mathrm{M}}=$ The coefficient depends on two parameters which are $S$ and $\beta$ where:

$$
S=\frac{\rho \omega D^{2}}{4 \mu}, \quad \beta=\frac{D}{d}
$$

Where:

$\rho=$ Mud density in slug $\mathrm{ft}^{-3}$
$\mu=$ Dynamic viscosity in slug $\mathrm{ft}^{-1} \mathrm{sec}$
$\omega=$ Circular frequency of rotation in rad sec
$\mathrm{d}=$ External diameter of drillcollar in $\mathrm{ft}$
$\mathrm{D}=$ Diameter of the wellbore in $\mathrm{ft}$

Values of $C_{M}$ and $H$ as a function of $\beta$ for selected value of S depicted by Yigit and Christoforou (1998) reveal that $\mathrm{C}_{\mathrm{M}}$ and $\mathrm{H}$ are 3.7 and 0.5 if $\mathrm{S}=2930$ and $\beta=1.32$, respectively at $100 \mathrm{rpm}$ circular frequency. Thus, the equivalent density of drillstring and damping ratio will be $20.32 \mathrm{slug} \mathrm{ft}^{-3}$ and 0.03 . It should be noted because of the low value of 1.32 for diameters ratio, the change in $\mathrm{S}$ due to change in $\omega$ have little influence on $\mathrm{C}_{\mathrm{M}}$ and $\mathrm{H}$ values. Hence, assuming the mean circular frequency $(\omega)$ is reasonable and is let to be $100 \mathrm{rpm}$ for drilling applications.

\section{REFERENCES}

Apostal, M.C., G.A. Haduch and J.B. Williams, 1990. A study to determine the effect of damping on finiteelement-based, forced- frequency-response models for bottomhole assembly vibration analysis. Proceedings of the 65th SPE Annual Technical Conference and Exhibition, Sept. 23-25, New Orleans, Louisiana, pp: 1-14.
Besaisow, A.A. and M.L. Payne, 1988. A study of excitation mechanisms and resonances inducing bottomhole-assembly vibrations. SPE Drill. Eng., 3: 93-101.

Burgess, T.M., G.L. McDaniel and P.K. Das, 1987. Improving BHA tool reliability with drillstring vibration models: Field experience and limitations. Proceedings of the SPE/ADC Drilling Conference, March 15-18, New Orleans, Louisiana, pp: 1-14.

Chen, S.S., M.W. Wambsganss and J.A. Jendrzejczyk, 1976. Added mass and damping of a vibrating rod in confined viscous fluids. Proceedings of the National Conference of Applied Mechanics, June 15-17, University of Utah, Salt Lake, pp: 5-5.

Dunayevsky, V.A. and F. Abbassian, 1998. Application of stability approach to bit dynamics. SPED Drill. Completion, 13: 99-107.

Dunayevsky, V.A., F. Abbassian and A. Judzis, 1993. Dynamic stability of drillstring under fluctuating weight on bit. SPE Drill. Completion, 8: 84-92.

Jansen, J.D., 1991. Non-linear rotor dynamics as applied to oilwell drillstring vibrations. J. Sound Vibration, 147: 115-135.

Khulief, Y.A. and H. Al-Naser, 2005. Finite element dynamic analysis of drillstring. Finite Elements Anal. Des., 41: 1270-1288.

Lee, H.Y., 1991. Reporting and wave propagation in borehole. MIT Department of Ocean Engineering.

Shyu, R.J., 1989. Bending of rotating drillstrings. Ph.D. Thesis, Massachusetts Institute of Technology.

Yigit, A.S. and A.P. Christoforou, 1996. Coupled axial and transverse vibrations of oilwell drillstrings. J. Sound Vibration, 195: 617-627.

Yigit, A.S. and A.P. Christoforou, 1998. Coupled torsional and bending vibrations of drillstrings subject to impact with friction. J. Sound Vibration, 215: 167-181. 